\title{
Tilburg Dutch vowel alternations and phonological elements
}

\author{
Francine Swets
}

Meertens Institute

\section{Introduction}

It is often useful to reconsider apparently fully analysed facts from a restrictive theoretical viewpoint. At first sight, representing the Tilburg vowel system using the elements A, I, U, which are used, for instance, in Dependency Phonology (see, for example, Anderson and Ewen 1987) and Government Phonology (see, for example, Harris 1994), would not seem to pose many problems. However, it turns out that this represention in phonological elements instigated a slightly different analysis of the phonological (vowel) system - distinct from that proposed in Van Oostendorp (2000), who was the first to propose not only a description but also an analysis of the vowel system of this dialect. It turns out that some problems that remained unanswered in the earlier analysis can now be accounted for.

In this article, I suggest that the shortening of long lax vowels caused by syllable structure is not the same as the laxing of tense vowels, at least not in this dialect. I propose that the alternation between forms with a tense and a lax vowel is a morphophonemic one, whereas the shortening process is truly phonological. I assume that at some stage in the history of Tilburg Dutch, the process of tense vowels becoming lax and vice versa was a productive, assimilatory, vowel harmonylike process, just like umlaut processes in this same dialect. Nowadays, it is no longer a productive phonological process; as a result, there is considerable variation and there are apparently some exceptions. Therefore, I claim that this might be an alternation that is no longer analysable in the (synchronic) phonology of the language, in spite of the fact that at an earlier stage it was.

The structure of the article is as follows. To begin with, I will present some data from Tilburg Dutch, with some necessary background information. For the data I will use the transcription suggested in the descriptive phonology of Tilburg by Boutkan and Kossmann (1996). Next, I will present the analysis by Van Oostendorp 
(2000) and point out where this analysis runs into problems. I will then propose an analysis based on elements and will demonstrate that this analysis not only captures the facts just as well as the Van Oostendorp analysis, but also can solve a problem that is apparently unsolvable in his analysis. In Section 5, after a short excursion into an older stage of the dialect, the conclusions are given.

\section{The Tilburg vowels}

Tilburg has 21 vowels, including the schwa, and has both tense and lax vowels. ${ }^{1}$ The lax vowels can be either long or short.

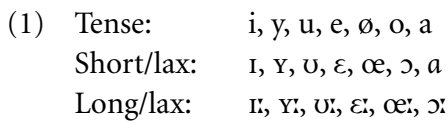

(based on Boutkan and Kossmann 1996)

There is an alternation between long lax and short lax vowels and between tense and lax vowels. These alternations can be found with both inflection and derivation (and compounding). Furthermore, there is a limited number of cases where umlaut applies. Some examples of diminutive alternations are given below.

(2) a. long lax/short lax alternation

$\begin{array}{ll}\text { binn } & - \text { bintja } \\ \text { leg } & - \text { leg-DIM }^{2} \\ \text { meit } & - \text { metjo } \\ \text { girl } & - \text { girl-DIM } \\ \text { porl } & - \text { poltja } \\ \text { pole } & - \text { pole-DIM }\end{array}$

b. tense/lax alternation

strep $\quad-$ stripkə (or strisp - strrpkə) $)^{3}$

stripe $\quad$-stripe-DIM

døk $\quad-$ dykskə (or dy:k - dykskə)

dent $\quad-$ dent-Dim

slop $\quad-$ slupkə (or slusp - slupkə)

pillowcase - pillowcase-DIM

c. umlaut

huk $\quad-$ hykskə

corner - corner-DIM

hok - høkskə

cage - cage-DIM

(Boutkan and Kossmann 1996:31-2) 
The umlaut-alternations are generally considered remnants from a previous stage of the language, when umlaut (or fronting) used to occur with certain stems before certain affixes. It probably used to be a productive phonological process but has now been reduced to an alternation that occurs only with some stems.

Van Oostendorp (2000) is, as far as I know, the only one to propose an explicit, synchronic analysis of the non-umlaut alternations in Tilburg Dutch. His proposal is based on the idea that both shortening of long lax vowels as well as laxing of tense vowels are caused by syllable structure. A long lax vowel shortens when, due to the addition of a consonant, there is no room left in the syllable for the long vowel. A tense vowel becomes lax when the syllable-rhyme becomes branching due to, for instance, affixation - i.e., a closed syllable/branching rhyme wants its head to be lax while an open syllable/non-branching rhyme demands a tense head. For Van Oostendorp, these alternations are therefore similar, though not the same. Both are phonological processes caused by, for instance, affixation. This affixation creates a certain type of syllable structure, which in turn causes laxing of the tense stem-vowel or shortening of the long lax stem-vowel. This proposal is presented under (3).

(3) a. stem /slsp/ ('sleep')

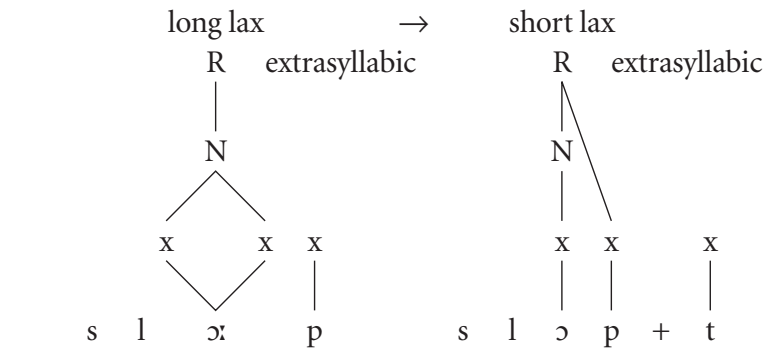

b. $\quad$ stem /spøl/ ('play')

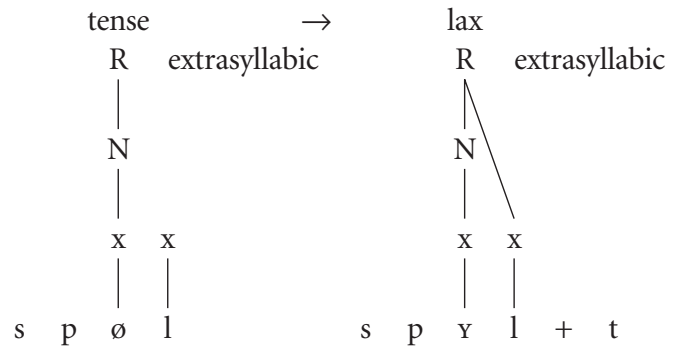

In (3a), the stem /slop/ ('sleep') has a long lax vowel. When the 3rd p. sg. inflectional /-t/ is added, the vowel shortens because the /- $\mathrm{t} /$ forces the final extrasyllabic consonant into the syllable, resulting in /slopt/. In (3b), the stem /spøl/ ('play') has a tense vowel, which cannot be the head of a branching rhyme. When an inflectional/-t/ is added, the tense vowel becomes lax because the /-t/ forces the final extrasyllabic consonant into the syllable, which therefore becomes branching and in need of a lax head. 
For Van Oostendorp, it is crucial that /I/ and /e/, /Y/ and /ø/ and / $/ \mathrm{e}$ and /o/ have the same phonological height; that is, they are all high. If not, the alternation between, for instance, /I/ and /e/ could not be expressed merely in terms of laxness. As a matter of fact, for Van Oostendorp (2000:32, 79), these alternations actually form one of the reasons to represent these vowels as such (besides the fact that an /e/ laxes to $[\mathrm{I}]$ and not to $\left[\mathrm{er}_{\mathrm{i}}\right]$ in $\mathrm{r}$-colouring and that /I/ and /e/ are the most susceptible to reduction to [ə]).

One of the advantages of the above-mentioned analysis is that it produces a regular pattern of alternations. The alternations themselves can be analysed as phonological processes in a morphological context, when, through affixing or compounding, a syllable structure is created where there is either no room left for a long lax vowel or the branching rhyme structure requires a lax instead of a tense head.

The Van Oostendorp analysis is, however, not free of problems. For instance, it appears to be the case that the alternations between long lax and short lax vowels are completely regular and free of exceptions. In contrast, the alternations with the tense/lax pairs do show some exceptions and variations, which are difficult to account for in his analysis. Some examples of such exceptional tense/lax alternations are presented below under (4): these are alternations for which there is apparently no need on the basis of the syllable structure.

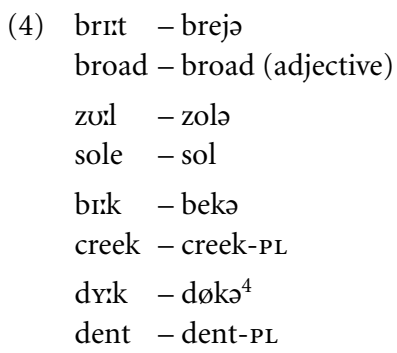

Forms such as shown in (4) suggest that there is not one phonological 'shortening' process, caused by syllable structure and consisting of either laxing of tense vowels or shortening of long lax vowels, but that we are dealing with two distinct processes. This is exactly the conclusion I reached when attempting to represent the Tilburg vowel system in phonological elements.

\section{Tilburg vowels in elements}

When we try to analyse the Tilburg Dutch vowel system in terms of elements, it becomes clear that the shortening of long lax vowels and the laxing of tense vowels are not two processes with a similar status. 
In order to make this clear, let us turn to the analysis of the Tilburg vowels in elements. I will make use of the elements A (openness), I (frontness), U (roundness) and the phenomenon of headedness (or lack of it) (cf. Polgárdi 1998, referring to Cobb 1997; for a similar but different view of Dutch vocalic structure in an elemental analysis, see Smith et al. 1989). The Tilburg vowel system can be seen as consisting of three vowel series (discarding the schwa): a series of short lax vowels, one of long lax vowels, and a series of tense vowels. In (5) an 'elemental' representation of the Tilburg vowel system (and the alternations in question) is suggested. The tense vowels are shown in (5a) and the lax vowels in (5b).

\begin{tabular}{|c|c|c|c|c|c|c|c|c|}
\hline a. i & $y$ & $\mathrm{u}$ & $\mathrm{e}$ & $\varnothing$ & $\mathrm{o}$ & & $\mathrm{a}$ & \\
\hline $\mathrm{x}$ & $x$ & $x$ & $\mathrm{x}$ & $\mathrm{x}$ & $x$ & & $\mathrm{x}$ & \\
\hline I & I & I & I & I & I & & 1 & \\
\hline I & $\underline{\mathrm{I}}$ & I & I & I & I & & I & \\
\hline & $\bar{I}$ & I & 1 & I & I & & I & \\
\hline & 1 & I & $\underline{\mathrm{A}}$ & $\underline{A}$ & $\underline{\mathrm{A}}$ & & $\underline{\mathrm{A}}$ & \\
\hline & 1 & I & & I & I & & & \\
\hline & $\mathrm{U}$ & $\underline{\mathrm{U}}$ & & $\mathrm{U}$ & $\mathrm{U}$ & & & \\
\hline & & & $\|$ & $\|$ & $\|$ & & & \\
\hline b. & & & I & $\mathrm{Y}$ & U & $\varepsilon$ & $œ$ & 0 \\
\hline & & & $\mathrm{x}$ & $\mathrm{x}$ & $\mathrm{x}$ & $\mathrm{x}$ & $\mathrm{x}$ & $\mathrm{x}$ \\
\hline & & & 1 & 1 & 1 & 1 & 1 & 1 \\
\hline & & & I & I & 1 & I & I & 1 \\
\hline & & & & 1 & 1 & 1 & 1 & 1 \\
\hline & & & & 1 & 1 & A & A & A \\
\hline & & & & 1 & 1 & & I & I \\
\hline & & & & $\mathrm{U}$ & $\mathrm{U}$ & & $\mathrm{U}$ & $\mathrm{U}$ \\
\hline
\end{tabular}

Each vowel gets a distinctive representation through the use of an element or a combination of several elements. The underlining of an element implies that that element is the head of a certain combination of elements.

In the representation in (5), we have not followed Van Oostendorp (2000) in his representation of $/ \mathrm{I}, \mathrm{Y}, \mathrm{U} /$. In his analysis the $/ \mathrm{I} /$, for instance, is crucially not high but mid. If we had followed his analysis in this respect, we would have had a problem. In the element analysis, headedness distinguishes between tense and lax vowels. Lax vowels are characterized by the fact that they do not have a head. If we had represented the lax vowels $/ \mathrm{I}, \mathrm{Y}, \mathrm{U} /$ as mid, it would have been difficult to distinguish between, for instance, $/ \mathrm{I}, \varepsilon, a /$ without making use of headedness. That is, if the /I/ is mid (as in the Van Oostendorp analysis), it must contain an A element, just like the $/ \varepsilon /$. So both would consist of an I and an A, and without being able to use headedness there would be no way to distinguish between them. As a solution I propose to analyse the $/ \mathrm{I}, \mathrm{Y}, \mathrm{U} /$ not as mid but as high, as can be seen in the representation in (5). 
On the basis of the representation in (5), the alternations change in an important way. If, for instance, we look at the examples presented in (2b) - repeated here for the sake of convenience in (6) - we notice that the alternations no longer consist of only laxing but of laxing and something like raising. This is because the /e/ consists of $\{\mathrm{I}, \mathrm{A}\}$ while the /I/ consists only of the element I. If the /e/ simply became lax because of the change in syllable structure, one would expect the resulting form to be $* / s t r \varepsilon p k ə /$, the form with the lax counterpart of /e/.

(6) strep - stripkə
$\mathrm{d} ø \mathrm{k}-\mathrm{dykskə}$
slop - slopkə

However, /strep/ does not turn into */strepkə/, nor do /døk/ and /slop/ become */dœkskə/ and */slopkə/, respectively. This is because the vowel not only becomes lax (that is, loses its headedness) but also becomes less low (loses its A element).

This process reminds us more of the umlaut/fronting found, for instance, with the diminutives than of the purely quantitative shortening found with the long lax vowels (e.g., $/ \mathrm{m} \varepsilon \mathrm{d} / \mathrm{m}-/ \mathrm{m} \varepsilon \mathrm{dj} /$ ). That is, both processes show exceptions and variations. Thus, the true umlaut alternations are known to be irregular and unproductive, just like the alternations given in (4). For instance, an alternation such as the one between /brid/ and /breja/ is not only unpredictable or unnecessary because of its syllable structure (thereby forming a problem for the Van Oostendorp analysis) but is also unpredictable on the basis of its vowel make-up. That is, not every stem-vowel / $\mathrm{u} /$ corresponds to /o/ in plural formation (cf. (7a)), and not every $/ a /$ corresponds to $/ \varepsilon /$ (through umlaut) in diminutive formation (cf. (7b)).

(7) a. zo: -zolə (example already given)

sole - sole-PL

but puit - puita

leg - leg-PL

b. man - menəkə

man - man-DIM

but vlam - vlamekə

flame - flame-Dim

As I would expect, both umlaut and laxing/tensing present alternations that are non-productive and neither umlaut nor tensing/laxing is free of exceptions.

Therefore, I suggest that in synchronic Tilburg Dutch, there is only one (instead of $t w o$ ) regular phonological shortening process. This process can be described more or less as follows: 'a long lax vowel shortens if its syllable becomes overlong as a result of, for instance, affixation. This process is, as would be expected, purely regular and free of exceptions. 
Besides this phonologically regular process, we find two other alternations in Tilburg Dutch. Neither of these is productive or regular, in spite of the fact that they may have been in some older stage of Tilburg Dutch. One of these alternations is based on umlaut or fronting - no one considers this alternation to be synchronically productive and regular. The other alternation, behaving in a similar fashion, is considered by Van Oostendorp to be phonologically regular and productive, just like the shortening processes. However, I claim that this is not the case: this 'unlowering' process is synchronically no longer productive and regular. It is therefore not similar to the phonological shortening processes but to the umlaut/fronting alternations. If this alternation were similar to the alternation due to the shortening process, we would expect the alternation to be caused by syllable structure, just as the shortening process is. However, as I have demonstrated, this is not the case: the lax alternant of the tense stem is not a product of laxing alone, but of laxing and raising.

\section{Excursion to an older stage of Tilburg Dutch}

Speculating about older forms of Tilburg Dutch, in which both umlaut/fronting and laxing/raising might still be phonologically regular, productive processes, I would propose something along the following lines to have been the case.

Boutkan and Kossmann (1996) seem to suggest that the raising alternation occurs mainly with diminutive suffixes and with the nominal plural and 2nd person verbal suffixes. We might assume that historically these nominal plural and 2nd person verbal forms consisted of a suffix with a high, lax vowel (containing the element I and no head). This suffix might have caused the stem vowel to lose its A element (which stands for openness) as well as its headedness. This speculation is supported for the verbal forms by Boutkan (1990), who points out the historical existence of a 2 nd and 3rd person inflectional suffix with a vowel /i/. Boutkan mentions that with some 'strong' verbs, the stem-vowel /e/ changed to /i/, as a consequence of an /i/ in the next syllable - a phenomenon called Proto-Germanic i-umlaut (Boutkan 1990, referring a.o. to Van Loon 1986). This would explain alternations such as /yeva/ - / yIft/ ('give' — 'gives'): as the suffix contains no A element and no head, the stem may not contain them either. In order to be in harmony with the suffix, the stem-vowel /e/ consisting of $\{\underline{A}, I\}$ loses both its A element and its headedness (or: loses its A-head).

With the diminutives, it might have been the case that stems not containing an I element (and therefore having no frontness in their phonological make-up) had an I added to them. The stems that already contained an I element (and therefore could not undergo fronting/umlauting because, in this framework, elements occur only once) lost their A elements instead. This would account for forms such as /huk/ - /hykskə/ (in which diminutive form the I element is added to the stem-vowel) 
but also for forms such as /strep/ - /stripkə/. Although, in this last example, umlaut/ fronting would be expected to cause addition of an I element, in this case the stem loses its A element because the /e/ already contains an I element ( $\{\mathrm{A}, \mathrm{I}\})$.

As already mentioned, these assumptions are speculative and require additional and more serious attention. However, they do not seem unreasonable and processes such as the loss of an element caused by the absence of that same element elsewhere in the word, have been reported for other languages as well (see for example Vennemann 1986 on Rückumlaut in Middle High German and Alderete 1999 on tonal mutation in Maasbracht Dutch). Of course, these processes assumed in an older stage of Tilburg Dutch are only of interest to us as far as they tell us something about what Tilburg Dutch used to be like and because they might therefore tell us something about the background of some seemingly exceptional cases in the synchronic situation (such as the umlaut/fronting and 'i-umlaut' cases). However, I do not imply that they play a role in the synchronic phonological processes of the language.

\section{Conclusion}

I have demonstrated that there are reasons to believe that in Tilburg Dutch, only one productive phonological vowel shortening process, 'forced' by syllable structure, takes place. In this process, a long lax vowel becomes short after, for instance, suffixation. If the right syllable structure is present, this process always takes place in a completely predictable fashion.

Furthermore, there are remnants of some older, no longer productive, processes. Among these are the alternations based on umlauting/fronting and alternations based on raising. These alternations take place in certain morphological contexts and are not completely regular and productive. An attempt to solve the remaining problems will have to be postponed to some future time.

\section{Notes}

* I would like to thank Marc van Oostendorp and Jeroen van de Weijer for their useful comments.

1. As the schwa is not relevant for my analysis, I will not discuss it any further. Furthermore, just like in other Germanic languages, the tense vowels have also been called long and the lax vowels short. I will not go into this discussion here.

2. DIM stands for diminutive; PL stands for plural (evidently, P stands for person, and sG for singular).

3. This variation is found between speakers. It is not clear who uses which form. 
4. Note, by the way, that in Boutkan and Kossmann (1996) both forms can also have tense vowels, e.g. /døk/ - /døkə/; /bek/ - /bekə/ and so forth. It is not clear whether this is indicative of a change in the direction of a more regular, synchronic phonological system (where no alternation between tense and lax should be found and we would expect the vowels to be lax in all forms) or whether the change is caused by the influence of Standard Dutch (where long lax does not exist and often corresponds to tense), 'encouraging' tense vowels to appear more often. Boutkan (p.c.) was unable to argue for any direction of change but seemed to consider an influence of Standard Dutch as quite possible (thus representing an instance of 'Hollandse expansie'). Further research would be needed here.

\section{References}

Alderete, J.D. (1999) Morphologically Governed Accent in Optimality Theory. Ph.D. diss.

Anderson, J.M. and Ewen, C.J. (1987) Principles of Dependency Phonology. Cambridge University Press, Cambridge.

Boutkan, D. (1990) Morfofonologische klinkerwisseling in het Tilburgs stadsdialect. Taal en Tongval 42: 46-60.

Boutkan, D. and Kossmann, M. (1996) Het stadsdialect van Tilburg. P.J. Meertens-Instituut, Amsterdam.

Harris, J. (1994) English Sound Structure. Blackwell, Oxford.

Loon, J. van (1986) Historische fonologie van het Nederlands. Leuven, Amersfoort.

Oostendorp, M. van (2000) Phonological Projection. A theory of Feature Content and Prosodic Structure. Mouton de Gruyter, Berlin.

Polgárdi, K. (1998) Vowel Harmony. PhD Diss. Holland Academic Graphics, The Hague.

Smith, N., Bolognesi, R., Leeuw, F. van der, Rutten, J., and Wit, H. de (1989) 'Apropos of the Dutch vowel system 21 years on'. In H. Bennis and A. van Kemenade, eds., Linguistics in the Netherlands 6, Foris, Dordrecht, 133-143.

Vennemann, T. (1986). Rückumlaut. In Kastowky, D. and Szwadesh, A. (eds.) Linguistics across historical and geographical boundaries. Mouton de Gruyter, Berlin, 701-723. 